\title{
Paediatric spirometry guideline of the South African Thoracic Society: Part 1
}

\author{
R Masekela, ${ }^{1} \mathrm{MB}$ BCh, MMed (Paeds), Dip Allergology (SA), Cert Pulmonology (SA) Paeds, FCCP, PhD; D Gray, ${ }^{2}$ MB CHB, FRACP, MPhil; \\ C Verwey, ${ }^{3} \mathrm{MB}$ ChB, FCPaeds (SA), Cert Pulmonology (SA) Paeds; A Halkas, ${ }^{4}$ MB ChB, FCPaeds (SA), MMed (Paeds), FCCP; \\ P M Jeena, ${ }^{5}$ MB ChB, FCPaeds (SA), Cert Pulmonology (SA) Paeds \\ ${ }^{1}$ Department of Paediatrics and Child Health, Steve Biko Academic Hospital and University of Pretoria, South Africa \\ ${ }^{2}$ Department of Paediatrics and Child Health, Red Cross War Memorial Children's Hospital and University of Cape Town, South Africa \\ ${ }^{3}$ Department of Paediatrics and Child Health, Chris Hani Baragwanath Academic Hospital and University of the Witwatersrand, \\ Johannesburg, South Africa \\ ${ }^{4}$ Private Practice, Krugersdorp Private Hospital, Krugersdorp, South Africa \\ ${ }^{5}$ Department of Paediatrics and Child Health, Inkosi Albert Luthuli Central Hospital and University of KwaZulu-Natal, Durban, South Africa
}

Corresponding author: R Masekela (refiloe.masekela@up.ac.za)

\begin{abstract}
Spirometry forms an important component in the diagnosis and management of pulmonary diseases in children. In the paediatric setting, there are different challenges in terms of performance and interpretation of good quality and reliable tests. An awareness of the physiological and developmental aspects that exist in children is necessary to improve the quality and reliability of spirometry. We reviewed the recommendations on the technical aspects of performing spirometry in children, from the available guidelines and clinical trials. The focus was on the indications, methods and the interpretation of lung function tests in children $<12$ years of age. Reliable lung function testing can be performed in children, but an awareness of the limitations, the use of incentives and a dedicated lung function technologist are necessary.
\end{abstract}

S Afr Med J 2013;103(12 Suppl 2):1036-1041. DOI:10.7196/SAMJ.7239

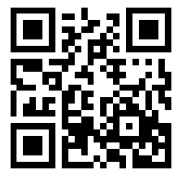

\section{Introduction}

Spirometry forms an important component in the diagnosis and management of pulmonary diseases in children and can be reliably performed in children as young as 2 - 4 years of age if adequately prepared. ${ }^{[1-5]}$ The reliability of spirometry requires adherence to strict standards with regards to equipment, data acquisition and interpretation. Standards have been published for older children and adults; ${ }^{[5,6]}$ however, both preschool and school-age children may have difficulty in meeting the quality-control criteria as set out in this guideline, hence the need for a paediatric-specific guideline.

In the paediatric setting, there are different challenges in terms of performing good quality and reliable tests. Young children have a smaller total lung volume and a larger airway size relative to lung volume than older children and adults. This means that forced expiration is completed in a shorter time in young children. The developmental stage of the child will also affect the ability to perform quality testing and an initial period of training is usually essential. Success is improved with a child-friendly approach, which may include the use of visual incentives and verbal encouragement. . $^{[4,7,8]}$

For this guideline, we reviewed the current literature on spirometry in children which included: a PubMed search of clinical trials on paediatric spirometry, a review of current American Thoracic Society (ATS) spirometry guidelines, European Respiratory Society (ERS) guidelines and the combined ATS/ERS task force guidelines. Each of the reviewers was allocated a section to review and any disagreements were resolved by consensus. The different sections were placed together in a working document and the guideline was sent to an independent reviewer for external review.

\section{Objective}

To discuss specific aspects in paediatric spirometry, which include: indications, methods and the interpretation of spirometry in children $<12$ years of age and to provide a guideline to healthcare practitioners in the South African context.

\section{Basic principles}

Prior to performing spirometry, adherence to some basic principles is necessary in terms of equipment care and use. All instruments should be calibrated or verified according to the manufacturer's recommendations and basic infection-control measures should be taken.

\subsection{Calibration and verification of instruments}

For accurate spirometry, equipment should meet the standardised recommendations for equipment accuracy and reliability (Table 1). ${ }^{[4,59]}$ Equipment should be calibrated routinely or verified according to the manufacturer's recommendation with this documented in the laboratory logbook. The accuracy of the calibration syringe should be checked annually.

\subsection{Display}

Visual inspection of the flow-volume curves and volume-time curves is essential for assessment of quality. It is optimal for the operator to be able to view these on screen during the test, but at a minimum before the next attempt. Ideally, the display should show forced vital capacity (FVC), forced expiratory volume in time, $t\left(\mathrm{FEV}_{t}\right)$, back-extrapolated volume (VBE) and time to peak expiratory flow (PEF) ${ }^{[4]}$ In preschool children, because they may expire their vital capacity in $<1 \mathrm{~s}$, FEV in $0.5 \mathrm{~s}\left(\mathrm{FEV}_{0.5}\right)$ should be displayed as well as the commonly used FEV in $1 \mathrm{~s}\left(\mathrm{FEV}_{1}\right)$. 
Table 1. The minimum requirements for accuracy with a spirometer and a pneumotachometer $^{*}$

\begin{tabular}{ll}
\hline Signal & Requirement \\
\hline Volume (pneumotachometer) & Check daily with 3 l calibration syringe \\
Range & $0-81$ \\
Accuracy & $\sim 3 \%$ or $\pm 50 \mathrm{ml}$, whichever is greater \\
Resolution & $25 \mathrm{ml}$ \\
Time & $15 \mathrm{~s}$ \\
Duration (for forced manoeuvre) & $\sim 1 \%$ \\
Accuracy & Check quarterly with 11 increments with \\
Flow & calibrating syringe \\
& $0-15 \mathrm{l} / \mathrm{s}$ \\
Range & $\sim 3.5 \%$ or $0.05 \mathrm{l} / \mathrm{s}$, whichever is greater \\
Accuracy & Log installation date and perform test with known \\
Software updates & subject
\end{tabular}

Table 2. Indications for spirometry in children*

\section{Diagnostic}

Detection of mechanical dysfunction in the respiratory system

Define the nature of the dysfunction (obstructive and mixed pattern)

Long-term monitoring of lung disease

Evaluation of disease outcome

Monitoring

Assessment of therapeutic interventions

Adverse reactions to drugs or injurious agents

Disability and impairment evaluation

To evaluate the risk of the diagnostic or therapeutic procedure

Public health

Derivation of reference ranges

Epidemiological surveys

Clinical research

${ }^{*}$ Adapted from Beydon et al. ${ }^{[4]}$ and Lange et al. ${ }^{[11]}$

\subsection{Infection control}

Hygienic measures are an essential part of the routine when dealing with spirometry. This includes universal control measures, such as hand washing and following the manufacturer's recommendations for cleaning of the spirometer. ${ }^{[9]}$ It is critical to keep the spirometer dry as fungi and bacteria thrive in moist environments. The use of bacterial filters between patients is mandatory to prevent contamination of equipment, as well as for the protection of the staff performing the spirometry. ${ }^{[10]}$ This is to prevent the spread of infectious diseases, in particular tuberculosis, which is highly prevalent in South Africa. The use of disposable filters is strongly encouraged.
Where re-usable filters are used, correct cleaning should be performed with agents recommended by the manufacturer, and filters should be allowed to dry completely before use in subsequent patients. ${ }^{[10]}$

\section{Indications}

Spirometry is a physiological test undertaken to assess the lung volume (both inspiratory and expiratory) of an individual measured as a function over time. Spirometry is performed for a variety of reasons (Table 2). Although spirometry is a valuable tool, alone it does not provide an aetiological diagnosis, and should be taken in the context of the history and the clinical presentation of the individual being assessed.

\section{Preparation of subjects}

Spirometry is a safe test and there are few reasons not to perform this test in children.

These include children with:

- an altered mental state ${ }^{[10]}$ or learning difficulties ${ }^{[2,3]}$

- chest, abdominal, oral or facial pain

- a $\geq 20 \%$ decrease in sequential $\mathrm{FEV}_{1}$ or FVC measurements on the same day. ${ }^{[5]}$

To obtain useful measurements, co-operation during spirometry is necessary. An initial period of training is essential. ${ }^{[4,7,12]}$ It is recommended to start testing patients at a young age as this provides training in good spirometry performance, which may lead to better results at an earlier age. ${ }^{[13]}$

Personal information such as height, weight, age, gender and racial group should be recorded for each patient. ${ }^{[11,14]}$ This information is necessary for the use of appropriate reference equations. The recently updated Global Lung Initiative (GLI) reference equations are the most comprehensive and should be used as they take into account the impact of racial differences in different population groups worldwide. ${ }^{[15]}$

Height should be measured to $0.1 \mathrm{~cm}$ accuracy, using a stadiometer for each patient. ${ }^{[16]}$ If standing height cannot be measured - e.g. in patients with severe spinal or thoracic cage abnormalities - the arm span may be used as an estimate of height. ${ }^{[10,11,17]}$

A skilled and trained technician who is used to working with children and a comfortable and safe environment are important factors in achieving successful spirometry in children. ${ }^{[3]}$ Children need adequate training and practise prior to being tested. Instructions need to be given in simple terms. The procedural steps for spirometry should be explained and demonstrated to the child. The use of child-friendly flow and volume incentive-based programmes may help achieve good results. ${ }^{[7,8,18}$

Children need to wear comfortable fitting clothes that do not impede their ability to inhale or exhale maximally. They should be in a seated position, allowing for less movement and interference with the test. In addition, most reference data are collected in the sitting position. The standing position should be avoided as this may lead to larger FVC values, especially in obese patients. ${ }^{[19]}$ A nose clip should be worn, ${ }^{[2,11,20]}$ but is not necessary if it does not fit properly or if it causes discomfort or anxiety; however, use, or lack thereof, should also be documented. A finger pinch of the nose is acceptable as long as this forms an adequate seal to the nose. The patient's neck needs to be held in a 
Table 3. Summary of test procedure*

\begin{tabular}{lcc}
\hline & \multicolumn{1}{c}{ Perform manoeuvre } \\
\hline Explain the test in a child-friendly manner & Exhalation only & Inhalation and exhalation \\
Use age-appropriate descriptions and stories & $\checkmark$ & $\checkmark$ \\
Place the mouth around the mouthpiece and close the lips to form a seal & $\checkmark$ & $\checkmark$ \\
Close the nose by using either a nose clip or 'finger pinch' & $\checkmark$ & $\checkmark$ \\
Start by breathing in and out as normal - 'easy breathing' at TV & $\checkmark$ & $\checkmark$ \\
Take a slow, deep inhalation to reach TLC & $\checkmark$ & $\checkmark$ \\
At TLC blow out as hard, fast and far (long) as possible & $\checkmark$ \\
When maximal expiration is met, fill up the lungs again by taking another quick, deep breath & $\checkmark$ \\
Repeat for a minimum of two (preschool child) or three (school-age child) acceptable \\
manoeuvres, but more are likely to be required - can continue if child is not distressed. \\
TV=tidal volume; TLC= total lung capacity. \\
${ }^{*}$ Modified from Beydon et al. ${ }^{[4}$ and Koegelenberg et al.
\end{tabular}

neutral position with neither hyperextension nor flexion..$^{[2,21]}$ The patient's mouth must be closed tightly around the mouthpiece and there must be no air leak from this seal. This may be problematic in patients with severe neuromuscular disease. In these cases, manual assistance may be mandated to obtain a good seal. ${ }^{[11]}$ There should be no chewing, vocalisation, swallowing, coughing or occlusion of the mouthpiece with the tongue, lips or teeth. ${ }^{[2]}$

Children should not engage in vigorous exercise prior to testing. Previous recommendations that a large meal prior to spirometry testing may affect results have been shown to be unjustified. ${ }^{[22]}$ Discontinuation of inhaled medication may be left up to the discretion of the doctor requesting the test and the indication for the spirometry. It is important that details of the medication taken on the day of testing are recorded. ${ }^{[1,1,15]}$

If the child is unable to achieve an adequate FVC but has a good rise on forced expiration, valuable information may still be obtained from the $\mathrm{FEV}_{1} \cdot{ }^{[4]}$ If the child is unable to perform spirometry adequately, he/ she should be given active encouragement, as this may enhance the chances of performing spirometry in future sessions.

\section{Data collection 6.1 Test procedure}

Standardised methods for performing forced exhalation manoeuvres is important for reliable results. Preschool and schoolage children may have difficulty achieving the traditional adult quality-control criteria; hence paediatric-specific definitions of test quality have been developed. ${ }^{[4,23]}$

The technologist must first demonstrate the procedure (Table 3 ) using child-friendly language and strategies. The procedure may

\author{
Table 4. Summary of within-manoeuvre acceptability criteria*

Unacceptable
Cough during first s of exhalation
Glottis closure
Incomplete exhalation
Sub-maximal effort
Leak around the mouthpiece or nose
Obstructed mouth piece
Free of artefacts or leaks
Start of test
Extrapolated volume of $<12.5 \%$ of FVC or $<80 \mathrm{ml}$, whichever is greater
Satisfactory exhalation
$3 \mathrm{~s}$ in children ( $1 \mathrm{~s}$ in preschool children) and/or
Plateau in the volume-time curve and/or
Subject cannot exhale further
${ }^{\text {FVC }}$ Modified from Beydon et al. ${ }^{[4]}$ and Koegelenberg et al. ${ }^{[5]}$

be either an exhalation-only manoeuvre only or an inhalation-exhalation manoeuvre, depending on the equipment available and information required. The child assumes the correct posture, puts the mouthpiece in his/her mouth and puts on the nose clip or closes his/ her nose with a finger pinch. It is important for the technician to inspect for any leaks around the mouthpiece or blocking of the mouthpiece by the tongue. The manoeuvre is begun with normal gentle tidal breathing. The child then takes a full, deep inspiration, aiming for total lung capacity (TLC), and then immediately gives a maximal 'blast' of expiration and a full exhalation, i.e. carries on breathing out until there is no air left. The technician can be guided by the flow-volume curve and should encourage the child to keep going' until the curve has flattened, denoting a volume plateau. Attaining a volume plateau is more important than the exhalation time in children ${ }^{[23]}$ Children are likely to have a shorter forced expiratory time (FET) than adults and hence the volume plateau may be completed in a shorter time: $3 \mathrm{~s}$ in children $<6$ years of age and $1 \mathrm{~s}$ in smaller, preschool children. ${ }^{[4,23]}$ Throughout the procedure the technician must ensure that there is no leak at or obstruction of the mouthpiece while the child exhales immediately after maximal inspiration using maximal effort and exhales fully to the end of test. The technician's assessment of the manoeuvre quality must be recorded. This is important in the analysis of the test. At least three repeatable forced expiratory manoeuvres should be recorded. For young children, two acceptable and reproducible curves are recommended rather than three (Fig. 1). ${ }^{[4]}$ 


\subsection{Test quality}

\subsubsection{Acceptability (within-manoeuvre}

A manoeuvre is technically acceptable if it has an unhesitating start, is free from artefacts and shows satisfactory exhalation (Table 4). An acceptable start of test demonstrates a rapid rise to $\mathrm{PEF}$ as seen as a sharp rise at the beginning of exhalation on the spirograms. The start of the test is quantified by the VBE. ${ }^{[5]}$ In children it is recommended that the VBE should be $<12.5 \%$ of FVC or $<80 \mathrm{ml}$, whichever is greater, ${ }^{[7]}$ which differs from the VBE of $<5 \%$ FVC and $<150 \mathrm{ml}$ required for adults. ${ }^{[5,23]}$ The volume-time and flow-volume loops generated should be free of artefacts. This includes no coughing, glottic closure or occlusion of the mouthpiece. Finally, there should be a satisfactory end-of-test - a maximal exhalation until no more air can be breathed out.

\subsubsection{Repeatability (between-manoeuvre evaluation)}

For diagnostic purposes there have to be two or three acceptable spirograms in preschool or school-age children, respectively. Repeatability is the closeness of results of repeated measurements and is achieved when the difference between the largest and next largest FVC is within $\leq 0.101$ or $10 \%$ of FVC with an FVC of $\leq 1.01$ or $\leq 0.150 \quad$ l for FVC $\geq 1.11 .^{[4,5]}$ Large variability between measurements is often due to incomplete inhalations or suboptimal efforts. At a minimum, the two or three best FVC evaluation)

manoeuvres should be saved for analysis. Although children may tire with repeated attempts, it is often necessary to attempt $\geq 10$ manoeuvres, provided that the child is not distressed or uncooperative. If the child is upset or distressed, testing should be stopped and the child praised for their effort. This will ensure possible satisfactory spirometry in the future.

\subsection{Selection of the best test}

The highest FVC and $\mathrm{FEV}_{1}$ from any of the acceptable manoeuvres should be reported. Flows should be reported from the manoeuvre with the largest sum of FVC and $\mathrm{FEV}_{1}$ or $\mathrm{FEV}_{0.5}$, if FET $<1 \mathrm{~s}$.

\subsection{Bronchodilator reversibility testing}

A bronchodilator response is an important test for demonstrating airway reversibility. An airflow reversibility test is performed using $400 \mu \mathrm{g}$ of $\beta 2$-agonist via a spacer device. The spirometry manoeuvre is then repeated as above after a minimum waiting period of $15 \mathrm{~min} \cdot{ }^{[24]}$ Recent reports have shown that maximal bronchodilator response occurs longer than $15 \mathrm{~min}$ after bronchodilator administration and probably a minimum waiting period of $20 \mathrm{~min}$ is preferable if possible within a busy clinic setting. ${ }^{[25]}$ An increase of $\mathrm{FEV}_{1}$ and/or FVC of $\geq 12 \%$ or $>200 \mathrm{ml}$ confirms bronchodilator response. ${ }^{[24,26]}$ However, the lack of response to a bronchodilator in the laboratory does

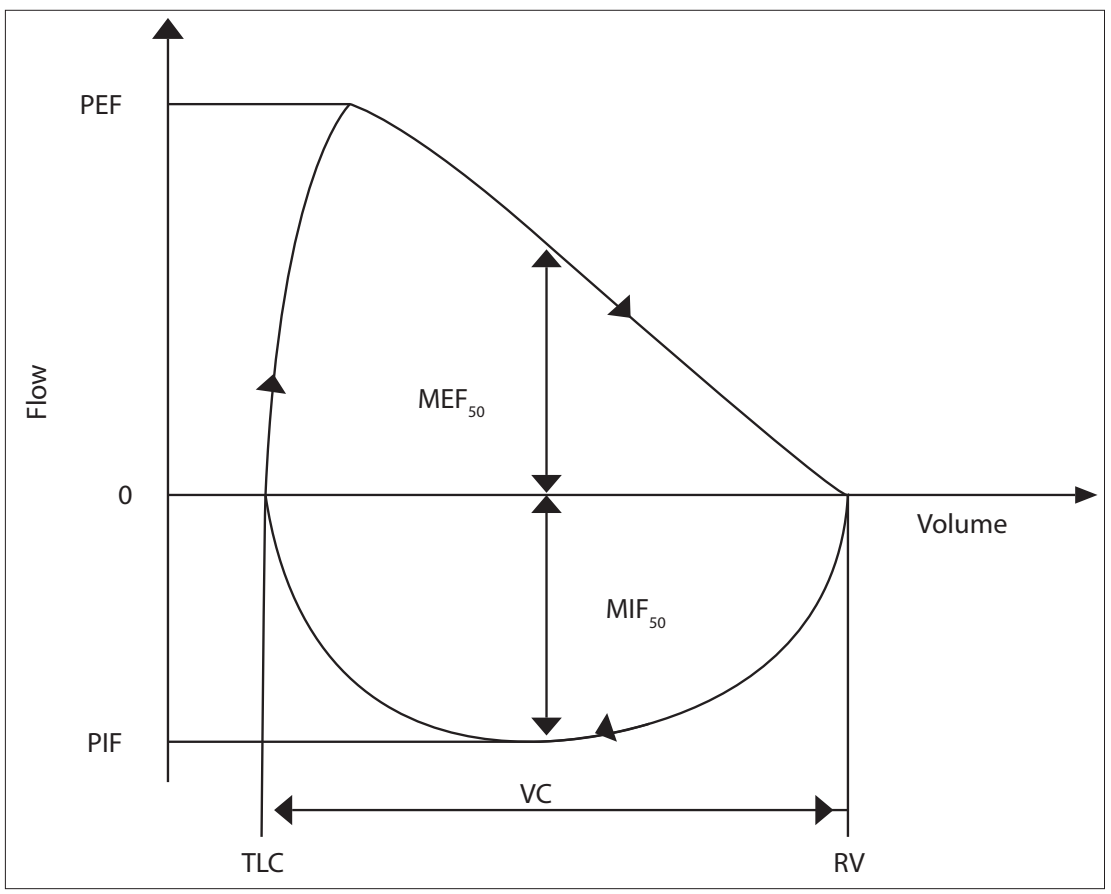

Fig. 1. Normal flow volume loop. $P E F=$ peak expiratory flow; $P I F=$ peak inspiratory flow; $M E F_{50}=$ maximal expiratory flow after $50 \%$ of expired forced vital capacity $(F V C) ; M I F_{50}=$ maximal inspiratory flow after $50 \%$ of expired FVC; TLC = total lung capacity; VC = vital capacity; $R V=$ raised volume. not preclude the lack of a clinical response. ${ }^{[27]}$ In young children, an increase in percentage from baseline rather than absolute volume is likely to be more useful. ${ }^{[4]}$ The use of flows such as the maximal expiratory flow (MEF) after $25-75 \%$ of expired FVC $\left(\mathrm{MEF}_{25-75 \%}\right)$ is not useful for measuring bronchodilator response, as these indices show high variability. In addition, they are based in part on the FVC and therefore are not interpretable if the FVC changes with a bronchodilator. ${ }^{[25]}$ They have also been found to have little clinical utility in adult patients with obstructive airway disease. ${ }^{[28}$

Negative results do not exclude the use of a bronchodilator or the diagnosis of asthma. It may be useful to repeat the test during an acute exacerbation. Bronchodilator responsiveness testing may be performed using various other direct and indirect challenges, but these are beyond the scope of this guideline.

\section{Reference criteria}

Pulmonary function testing varies with age, gender, height and ethnicity and therefore needs to be compared with predicted values appropriate for the individual being tested. A plethora of spirometric equations have been published (http://www.lungfunction. org/tools.html); however, there remains a paucity of suitable equations for the South African population with attempts to correct for ethnic differences being over-simplistic, especially among younger children. ${ }^{[29]}$ In addition, few equations take into account the changes that occur with height during the adolescent growth spurt, ${ }^{[30,31]}$ with many equations being limited to different age groups. This lack of continuity across ages has been addressed in the new equations published through the GLI. ${ }^{[16]}$

These equations use large numbers of participants from 33 countries across the whole age range ( 3 - 95 years) and use of up-to-date methods. The equation is limited by the fact that it currently does not include data from Southern African populations; however, it is currently the most robustly developed equation with continuity across ages. Until Southern African data have been included in these equations, it is recommended that the equation for other ethnicities be used. Industry has been involved in the development of these equations and most spirometric equipment manufacturers will easily be able to add these to their software programs if not already provided. It is important to note that there is higher intra-subject variability among children than among adults. The betweensubject coefficient of variation for FEV 


\section{GUIDELINE}

decreases from $17 \%$ at 3 years to $11 \%$ at 20 years. The lower limit of normal for $\%$ predicted $\mathrm{FEV}_{1}$ is $66 \%$ for a 3-year-old and $78 \%$ for a 20 -year-old. ${ }^{[32,33]}$ It is therefore recommended that results in children should be expressed as $Z$-scores or centiles. As disease severity-grading currently uses \% predicted, it may be useful for clinicians, if both $Z$-scores and \% predicted are included on spirometry reports.

\section{Interpretation of spirometry in children} 8.1 Obstructive pattern

There is a disproportionate reduction of maximal airflow from the lungs in relation to maximal volume expired during the forced manoeuvre, defined as $\mathrm{FEV}_{1} / \mathrm{FVC}$ or $\mathrm{FEV}_{0.5} / \mathrm{FVC}$ below the 5 th percentile of the predicted or $<80 \%$. ${ }^{[2]}$ This gives a concave appearance to the flow volume loop (Fig. 1). When $\mathrm{FEV}_{1}$ and FVC are both concomitantly decreased, it suggests that the patient did not inhale maximally or exhale long enough.

If there is central and upper airway obstruction, there is a reduction in PEF and increased $\mathrm{FEV}_{1} / \mathrm{PEF}$. This can be observed as a reduction in size, which is observed on both the forced inspiratory and expiratory flow loops. In extrathoracic airway obstruction, the reduction is pronounced for the maximum inspiratory flow volume loop, while in intrathoracic airway obstruction, reduction is pronounced in the $\mathrm{MEF}_{50}$ (Fig. 3).

The assessment of severity of obstructive defects is based on the \% predicted $\mathrm{FEV}_{1}$ (Table 5) and is based on adult studies. ${ }^{[25]}$

\subsection{Restrictive pattern}

Spirometric restriction can only suggest restrictive lung disease and requires further assessment of lung volumes to confirm the diagnosis (Fig. 4). This pattern can either demonstrate a restrictive pattern or a suboptimal effort in someone with normal lung function. Restrictive lung function occurs with reduction in TLC and no obstruction to flow. A restrictive pattern on spirometry is defined as $\mathrm{FEV}_{1}$ / FVC $>85-90 \% .{ }^{[25]}$ Assessing the FVC can be helpful if:

- $\%$ predicted $\mathrm{FVC}$ is $>80 \%$ then there is either normal or poor effort on lung function testing

- \% predicted FVC is $<80 \%$ then this demonstrates a restrictive pattern.

In severe obstructive disease FVC may be $<80 \%$ and the $\mathrm{FEV}_{1} / \mathrm{FVC}$ would also be decreased.

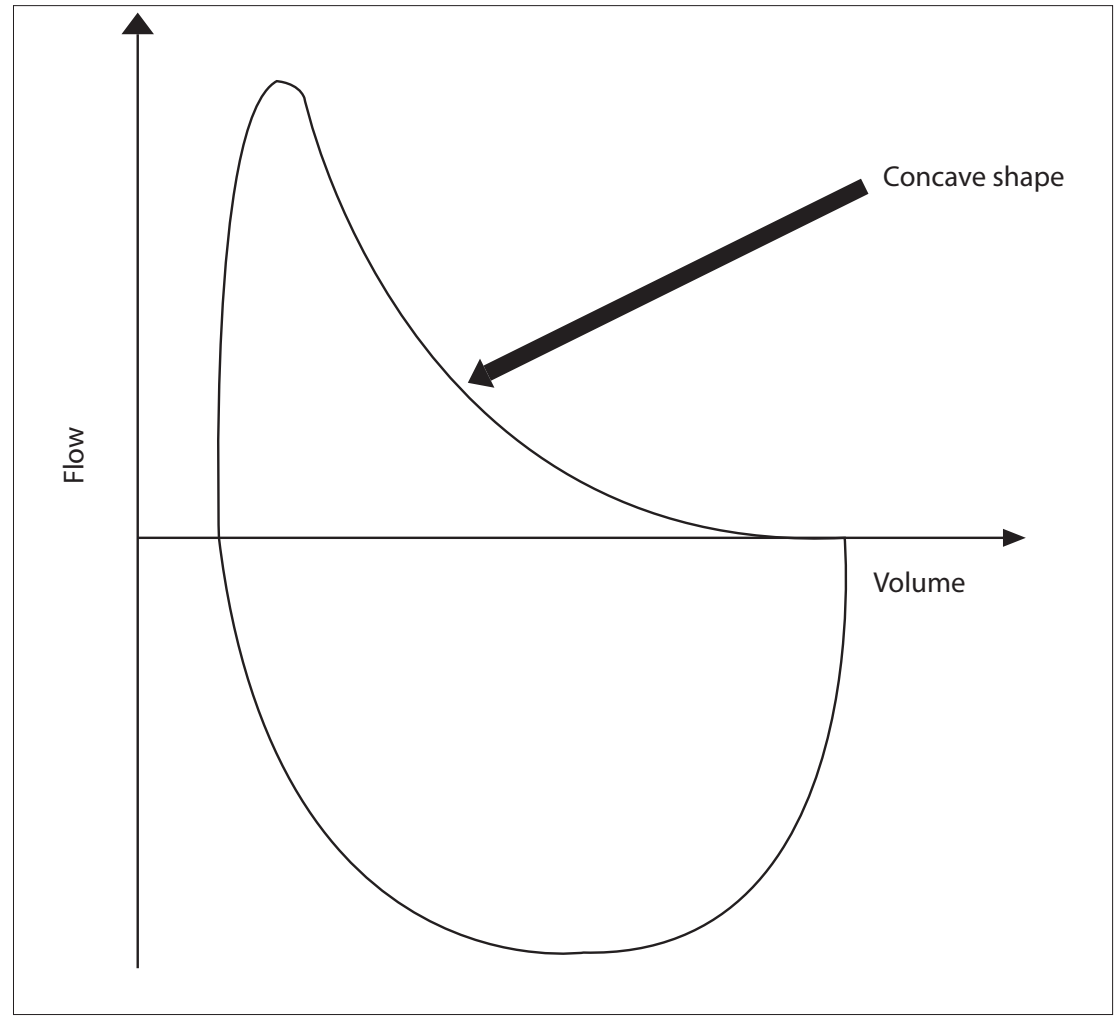

Fig. 2. Flow volume loop indicating obstructive airway disease.

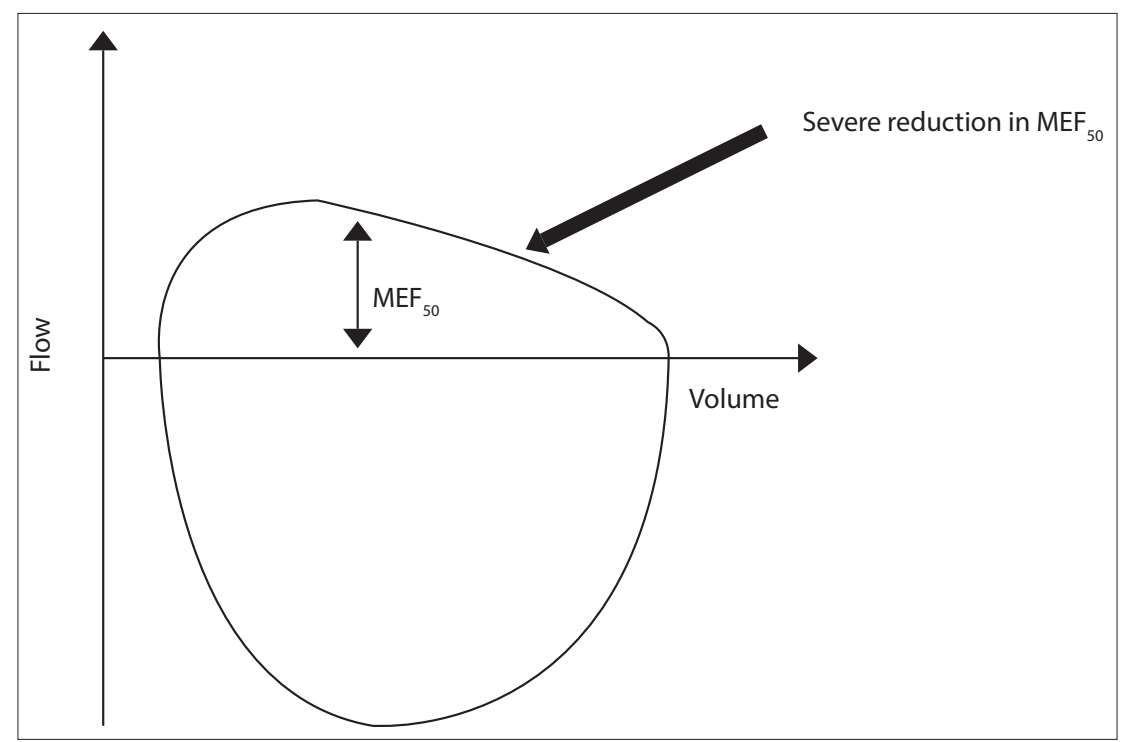

Fig. 3. Flow volume loop indicating intrathoracic airway obstruction. $M E F_{50}=$ maximal expiratory flow after $50 \%$ of expired forced vital capacity.

\subsection{Mixed pattern}

A mixed lung function abnormality describes the coexistence of obstruction and restriction. Children with this pattern will have both a reduced $\mathrm{FEV}_{1} / \mathrm{FVC}$ and $\mathrm{FVC}>80 \%$ predicted or $<5$ th percentile of predicted. ${ }^{125}$ The reduced vital capacity could be either due to hyperinflation or a restricted lung volume. This is important to understand in the interpretation of the test. Treatment of reversible obstruction may aid assessment. Accurate assessment of lung volumes with plethysmography would define the pattern more clearly.

\section{Special diagnostic tools for assessing lung function in children}

Spirometry has the disadvantage of being relatively insensitive in detecting early 


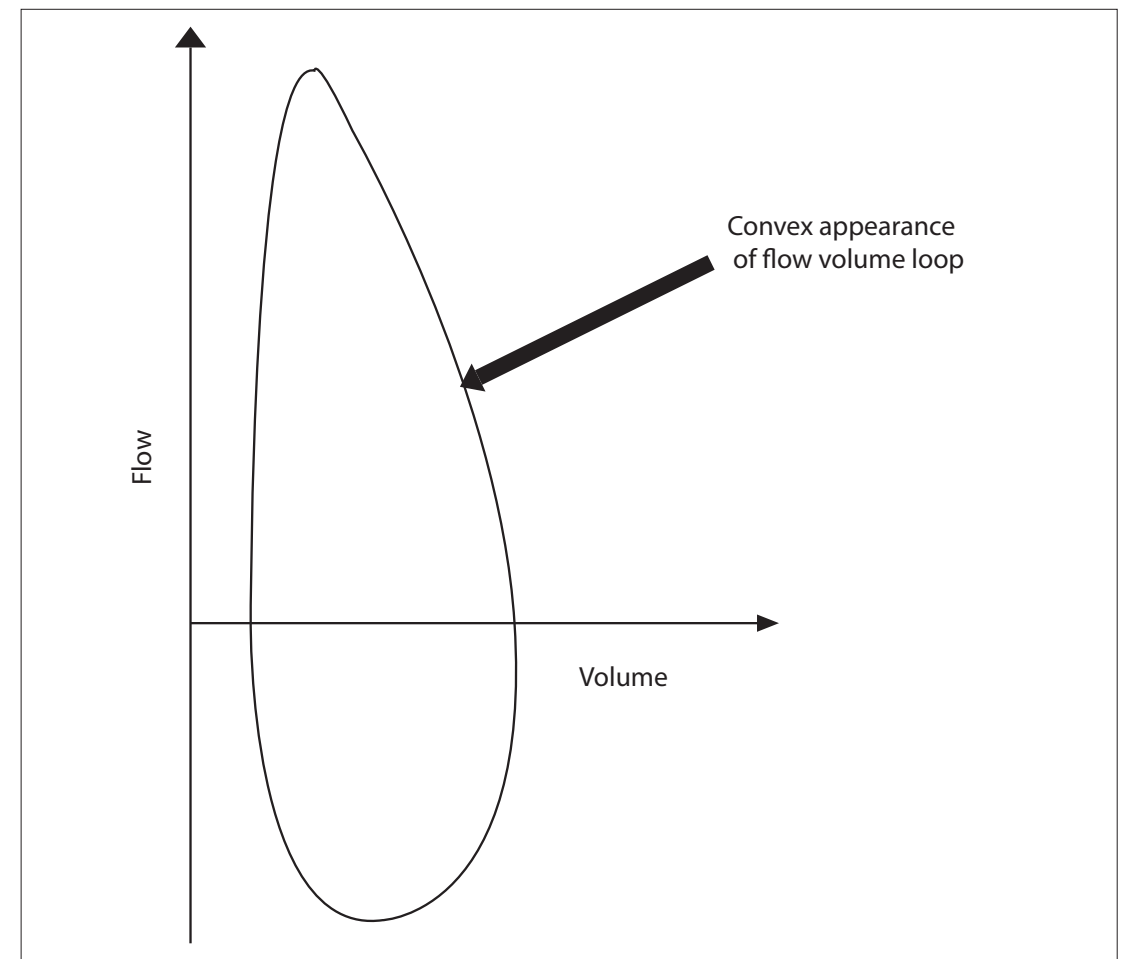

Fig. 4. Flow volume loop indicating restrictive lung disease.

Table 5. Grading of severity of obstructive airway disease based on adult ATS/ERS recommendations ${ }^{[25]}$

\begin{tabular}{ll}
\hline Grading & FEV1, \% predicted \\
\hline Mild & $70-80$ \\
Moderate & $60-69$ \\
Moderately severe & $50-59$ \\
Severe & $35-49$ \\
Very severe & $<35$ \\
ATS = American Thoracic Society: ERS = European \\
Respiratory Society; FEV F $_{1}=$ forced expiratory volume \\
in 1 1 s.
\end{tabular}

lung disease where $\mathrm{FEV}_{1}$ is still relatively preserved, e.g. in cystic fibrosis. There are newer techniques for the measurement of lung function; particularly where spirometry is difficult to perform or is too insensitive to measure early lung disease. These include infant spirometry (raised volume rapid thoracoabdominal compression (RVRTC)), plethysmography, multiple breath inert gas washout tests, forced oscillation technique and the interrupter technique. These are beyond the scope of this guideline and will be discussed in Part 2 of this series on paediatric lung function testing.

\section{Conclusion}

Performance of reliable lung function testing in children is possible. There are specific protocols that need to be followed in terms of calibration of equipment and quality assurance measures to ensure that reliable and reproducible spirometry is performed in children. This guideline has provided some guidance for performing spirometry in South African children. There is an urgent need to collect data on South African children to have local reference ranges to ensure quality of data collected.

Acknowledgements. We acknowledge the contribution of Proff Graham L Hall and Heather Zar for their critical review of the manuscript and constructive suggestions, which have improved the quality of the guideline.

\section{References}

1. Castille RG. Pulmonary Function Testing in Children. In: Chernick V, Boat TF, Wilmott RW, Bush A, eds. Kendig's Disorders of the Respiratory Tract in Children. Philadelphia: Saunders Elsevier, 2006:168-185.

2. Beydon N. Pulmonary function testing in young children. Pediatr Respir Rev 2009;10(4):208-213. [http://dx.doi.org/10.1016/j. prrv.2009.03.001]

3. Paton JY. A practical approach to the interpretation of lung function testing in children. Paediatr Respir Rev 2000;1(3):241248. [http://dx.doi.org/10.1053/prrv.2000.0055]

4 Beydon N, Davis SD, Lombardi E, et al. An official American Pulmonary function testing in preschool children. Am Respir Crit Care Med 2007;175(12):1304-1345. [http://dx.doi. org $/ 10.1164 / \mathrm{rccm} .200605-642 \mathrm{ST}]$

5. Koegelenberg C, Swart F, Irusen EM. Guideline for office [http://dx.doi.org/10.7196/samj.6197]

6. Miller MR, Hankinson J, Brusasco V, et al. Standardisation of spirometry. Eur Respir J 2005;26(2):319-338. [http://dx.doi.org 10.1183/09031936.05.00034805]

7. Aurora P, Stocks J, Oliver C, et al. Quality control for spirometry in preschool children with and without lung disease. Am J Thoracic Society/European Respiratory Society statement spirometry in adults, 2012. S Afr Med J 2012;103(1):52-62.
Respir Crit Care Med 2004;169(10):1152-1159. [http://dx.doi. org/10.1164/rccm.200310-14530C]

8. Vilozni D, Barker M, Jellouschek H, et al. An interactive computeranimated system (SpiroGame) facilitates spirometry in preschoo animated system (SpiroGame) facilitates spirometry in preschoo
children. Am J Respir Crit Care Med 2001;164(12):2200-2205. children. Am J Respir Crit Care Med 2001;164(12):2
[http://dx.doi.org/10.1164/ajrccm.164.12.2101002]

[http://dx.doi.org/10.1164/ajrccm.164.12.2101002] 9. Eber E, Zach MS. Spirometry: Volume-time and Flow-volume
Curves. In: Hammer J, Eber E, eds. Progress in Respiratory Curves. In: Hammer J, Eber E, eds. Progress in Respiratory
Research, Vol. 33: Paediatric Pulmonary Function Testing Basel: Karger, 2005;33:94-102

10. Canakis AM, Ho B, Ho S, et al. Do in-line respiratory filters protect patients? Comparing bacterial removal efficiency of six filters. Pediatr Pulmonol 2002;34(5):336-341. [http://dx.doi. org/10.1002/ppul.10171]

11. Lange NE, Mulholland M, Kreider ME. Spirometry: Don't blow it! Chest 2009;136(2):608-614. [http://dx.doi.org/10.1378/ chest.08-2315]

12. Eigen $\mathrm{H}$, Beiher H, Grant D, et al. Spirometric pulmonary function in healthy preschool children. Am J Respir Crit Care Med 2001;163(3):619-623. [http://dx.doi.org/10.1164/ ajrccm.163.3.2002054]

13. Kirby GS, Rosenfeld $M$, Ren CL, et al. Lung function distinguishes preschool children with $\mathrm{CF}$ from healthy controls in a multi-center setting. Pediatr Pulmonol 2012;47(6):597-605. [http://dx.doi.org/10.1002/ppul.21589]

14. Miller MR, Crapo R, Hankinson J, et al. General consideration for lung function testing. Eur Respir J 2005;26(1):153-161. [http://dx.doi.org/10.1183/09031936.05.00034505]

15. Quanjer PH, Stanojevic S, Cole TJ, et al. Multi-ethnic reference values for spirometry for the 3-95-yr age range: The global lung function 2012 equations. Eur Respir J 2012;40(6):1324-1343 [http://dx.doi.org/10.1183/09031936.00080312]

16. Quanjer PH, Hall GL, Stanojevic S, et al. Age-and height-based prediction bias in spirometry reference equations. Eur Respir J

2012;40(1):190-197. [http://dx.doi.org/10.1183/09031936.00161011]
Hibbert ME, Lanigan A, Raven J, Phelan PD. Relation of armspan to height and the prediction of lung function. Thorax
arme armspan to height and the prediction of lung function. Tho

18. Vilozni D, Barak A, Efrati O, et al. The role of computer game in measuring spirometry in healthy and 'asthmatic' preschool children. Chest 2005;128(3):1146-1155. [http://dx.doi
. org/10.1378/chest.128.3.1146]

19. Gudmundsson G, Cerveny M, Shasby DM. Spirometric value in obese individuals: Effects of body position. Am J Respir Care Med 1997;156(3):998-999. [http://dx.doi.org/10.1164/ ajrccm.156.3.9609089]

20. Chavasse R, Johnson P, Francis J, et al. To clip or not to clip? Noseclips for spirometry. Eur Respir J 2003;21(5):876-878. [http://dx.doi.org/10.1183/09031936.03.00048303]

21. American Thoracic Society. Lung function testing: Selection American Thoracic Society. Lung function testing: Selection
of reference values and interpretative strategies. Am Rev Respir Dis 1991;144(5):1202-1218. [http://dx.doi.org/10.1164/ Respir Dis 1991;1445)

22. Chu E, Burton D, McArdle N, Gain K. Recent consumption of a large meal does not affect measurements of lung function. Respirology 2010;15(6):947-951. [http://dx.doi.org/10.1111/ j.1440-1843.2010.01796.x]

23. Arets HG, Brackel HJ, van de Ent CK. Forced expiratory manoeuvres in children: Do they meet ATS and ERS criteria for spirometry? Eur Resp J 2001;18(4):655-660. [http://dx.doi.org/10 $1183 / 09031936.01 .00204301]$

24. Pellegrino R, Viegi $G$, Brusasco R, et al. Interpretative strategies for lung function tests. Eur Respir J 2005;26(5):948-968. [http:// dx.doi.org/10.1183/09031936.05.00035205

25. Stavreska V, Verheggen M, Oostryck J, et al. Determining the time to maximal bronchodilator response in asthmatic children. J Asthm 2009;46(1):25-29. [http://dx.doi.org/10.1080/02770900802460555]

26. Dales RE, Spitzer WO, Tousignaut $\mathrm{P}$, et al. Clinical interpretation of airway response to a bronchodilator: Epidemiological
of ales Re, Spitzer WO, Tousignaut $\mathrm{P}$, et al. Clinical interpretation of airway response to a bronchodilator: Epidemiological
considerations. Am Rev Respir Dis 1988;138(2):317-320. [http:// dx.doi.org/10.1164/ajrccm/138.2.317]

27. Pellegrino R, Rodarte JR, Brusasco V. Assessing the reversibility of airway obstruction. Chest 1998;114(6):1607-1612. [http:// dx.doi.org/10.1378/chest.114.6.1607]

28. Boggs PB, Bhat KD, Vekovius WA, Debo MS. The clinical significance of volume-adjusted maximal mid-expiratory flow (isovolume $\mathrm{FEF}_{\left.25-75^{4}\right)}$ in assessing airway responsiveness to inhale bronchodilator in asthmatics. Ann Allergy 1982:48(3):139-142.

29. Stanojevic S, Wade A, Cole TJ, et al. Spirometry centile charts for young for young caucasian children: The asthma UK collaborative nitiative. Am J Respir Crit Care Med 2009;180(6):547-552
[http://dx.doi.org/10.1164/rccm.200903-0323OC]

30. Degroodt EG, Quanjer $\mathrm{PH}$, Wise $\mathrm{ME}$, van Zomeren $\mathrm{BC}$ Changing relationships between stature and lung volumes during puberty. Respir Physiol 1986;65(2):139-153. [http://

dx.doi.org/10.1016/0034-5687(86)90046-0]
1. Wang X, Dockery DW, Wypij D, et al. Pulmonary function growth velocity in children 6 to 18 years of age. Am Rev Respi ajrccm/148.6_Pt_1.1502] Stanojevic S, Wade A, Stocks J, et al. Reference ranges for spirometry across all ages: A new approach. Am J Respir Crit rccm.200708-1248OC]

33. Stanojevic, S, Wade A, Stocks J. Reference values for lung function: Past, present and future. Eur Respir J 2010:36(1):12-19. [http://dx.doi.org/10.1183/09031936.00143209] 